\title{
GENERATION Y PREFERENCES IN ONLINE CONTENT CONSUMPTION: CONTENT MARKETING IMPLICATIONS FOR THE ARTS Edita Štrbová', Simona Boldišová
}

\begin{abstract}
This paper focuses on analysing the specific attributes and applications of content marketing in social media. Through an engaging and targeted content strategy using the "personas", this kind of marketing creates an engaged and motivated audience both in the commercial and non-commercial environment. The social networks are an appropriate environment and a tool for distributing and promoting content, including arts. The aim of our research was to use an online questionnaire to describe the behaviour of Generation Y (25-40 years) when using online content and identify their preferences. We also characterize the current state and future direction of content marketing in the Slovak conditions and the possibility of its use in the realm of arts.
\end{abstract}

Keywords: Generation Y, social media, content marketing, arts

\section{INTRODUCTION}

This specific type of marketing, which has appeared in the recent years, was until recently the domain of large multinational corporations, but today it is also used by medium-sized and small businesses, and thus it receives increasing attention by the marketers themselves. The concept of content marketing appears to be new and unknown, but quite the opposite is the case. Content marketing collectively shelters the activities directly related to content: any word, image, or pixel that can be engaged with by another human being, whether within the traditional forms of marketing communication (newspapers, magazines, etc.) or digital platforms (websites, social networks). In the context of this article, "content is compelling content, that informs, engages, or amuses" [Pulizzi, 2013, p. 10].

When defining content marketing, our definitions are derived from those presented by various authors with the endeavour to capture its essence. According to J. Pulizzi, the founder of Content Marketing Institute [2013, p. 9], "Content marketing is the marketing and business process for creating and distributing content to attract, acquire, and 
engage a clearly defined and understood target audience - with the objective of driving profitable customer action." According to this author, "Good content marketing makes a person stop, read, think, and behave differently" [ibid. p 10]. Instead of constantly offering products or services to the customers, we provide them with information that expands their knowledge of the products or services prior to the actual purchase. "If we provide the consumers with a consistent, relevant and valuable information, they will reward us - they will decide to buy the product or service from us." [Kuenn, Kuenn, 2015, p. 30]. S. Patel [2014] adds that content that is not intended for a direct purchase should be informative, enlightening, educational or entertaining. By publishing such content, we get the attention of the potential customers and, at the same time, encourage the existing ones to repeat their purchases. However, it is necessary to offer such topics that are directly related to our business, thereby presenting our expertise to the audience, or making them know us more deeply. According to B. Clarke [2014], ${ }^{3}$ the essence of content marketing lies in "...creating and distributing valuable content for free to attract the Internet users, some of which may later become your regular customers. The content you create is closely linked to what you sell or offer. In other words, in content marketing, you're trying to educate the people so that they get to know you, develop sympathy for you, and trust you enough to do business with you."

According to the above definition the essence of content marketing lies in the creation and publication of information that promotes trust and builds relationships with the audience in such a way that both potential and current customers develop a sympathy for the brand. This is not just about writing new articles, but rather about an elaborate marketing strategy that helps the companies become a leader in their field and sell without traditional "forced" sales techniques. And although content marketing is not primarily focused on selling products or services, it ultimately leads to this goal.

However, if we perceive content marketing from a non-profit perspective, according to C. Steele [2018], "designing engaging content is essential to growing every business, no matter the industry. Nowadays, every sector is influenced by the use of technology and utilizing digital means to grow a brand. In order to delight and attract more people to the arts and culture sector, organizations need to realize how important content marketing is in creating widespread awareness. " 4

In the current understanding of marketing and marketing communication, the customer is one of the key concepts. The former analysis of the sales cycle and customer segmentation differs significantly from the modern understanding especially as the customers today continuously receive information on the Internet and social networks. According to Radimák [2014], content marketing is a marketing strategy based on content that the people on the Internet search for and share. This makes it possible to thoughtfully use the fact that most strategic purchasing decisions are made on the Internet when searching for information about products and services. And although in the past the customers were viewed mainly in terms of the traditional socio-demographic indicators such as gender, age, place of residence, marital status, income or employment when planning the marketing communications, contemporary companies are focusing on adequately determining a plethora of segmentation criteria, including the behavioural and psychographic ones. Likewise, R. Rose [2018] argues that "It's critical to go beyond traditional segmentation of demographics when defining target audience." Modern content marketers should therefore view the customer in a broader context and try to identify the target group against the backdrop of the process of its socialization in a given culture. This implies the need for examining and understanding the specific motives, interests, values, shopping styles and habits, forms of learning, attitudes and social norms applica-

https://copyblogger.com/content-marketing/ [online: December 15, 2019]

https://www.culturepartnership.eu/en/article/how-to-use-content-marketing-to-share-arts [online: August 25, 2020] 
ble in a particular target market and/or audience or social group. "The art of virality lies not only in funny and interesting content, but also in its targeted impact on the target audience. And that's one of the many basic features of good content marketing" [Řezníček, Procházka, 2014, p. 21].

As a key element in the content marketing strategy for which content is made and created, the audience should be perfectly described and understood, and possible alternatives should be suggested to deal with its current problems. We strive to answer the audience's questions in a timely and accurate manner, teach the audience something new, and entertain it at the same time. Through this kind of communication, we create the prerequisites for building a mutual and confidential relationship. "The purpose of content marketing is to create interesting information your customers are naturally interested in, and thus naturally interested in you" [Pullizi in Řezníček, Procházka, 2014, p. 23].

If the target audience comprises people with interest in art and culture, the organizations must also be aware of the importance of content marketing when raising the awareness of a particular artwork, its author or the institution that conveys art to the audience.

However, it is just not enough to specify the target group when creating the content marketing strategy. Content marketing uses the so-called "persona" as an effective tool to define the typical representative of the target audience, a particular person, the embodiment of an ideal customer, which helps to more effectively target the creation and dissemination of content [Hrdličková, 2015]. The original definition of the term "persona" from 2002 states that:

"Buyer personas are research-based archetypal (modelled) representations of who buyers are, what they are trying to accomplish, what goals drive their behaviour, how they think, how they buy, and why they make buying decisions. (Today, I now include where they buy as well as when buyers decide to buy.)" [Zambito, 2013, online].

According to R. Rose [2018], "buyer persona development is a critical part of helping product- and service-focused marketers get an understanding of how to bring their product into the marketplace." At the same time, however, the author states that this concept only provides limited answers for content marketing. "Instead, as we develop personas, what if we started with the customer's need at the centre of the story? In other words, what if rather than starting with an answer - and then attempting to figure out how we lead the audience to get to that answer - we started with the question. What if we started with the audience's interests, challenges, and questions - and then figured out what our unique answer to them might be." [Rose, 2018, online]. This claim builds on the above need to use multiple segmentation criteria.

The target group consists of several specific personas for which unique content is created separately. The persona therefore does not replace the target audience but extends its quality for a more accurate targeting of content. The characteristics of specific customers are not simple; they are based on target groups and, at the same time, take into account the questions the customers ask when making a purchase or relevant decisions. This way, the personas can be found directly in the stores, online forums close to our focus, or on social networks. D. Bayer [2016] argues that although the personas are mostly unrealistic, their profiles and data are based on real-world data collected from market research, own experience or customer databases. There are several ways to find out all the information about personas, but the qualitatively oriented interviews and questionnaire surveys are considered to be the most effective.

Today's world full of technological innovation sparks the changes in human behaviour, which in turn affects the world of trade, including the marketers. An [2016] states that in the mid-1990s access to the Internet changed the way people searched for and consumed information, and marketers had to develop a whole new way of online marketing. In the early 21 st century, millions of people were able to connect thanks to the 
social networks, and the marketers had to respond to this phenomenon and work with the customers in the best possible ways with consideration to future prospects. Later, with the advent of smartphones, the public has been granted an immediate access to everything the Internet has to offer regardless of where they are. The marketers therefore had to ensure that their content was also compatible with mobile devices. The changes that affect the use of the Internet are becoming increasingly frequent and they affect consumer behaviour in the online environment. Therefore, we have decided to take a closer look at this issue.

\section{Methods}

We used the above theoretical outcomes to define our research problem: characterization of the current status and future outlooks in Slovak content marketing. The research is based on the questionnaire survey titled "The Future of Content Marketing: How People Are Changing the Way They Read, Interact and Engage with Content"[An, 2016, online], which was implemented by HubSpot in 2016 as an online survey of online users from around the world $(\mathrm{N}=1091)^{5}$. The population sample with Slovak respondents $(\mathrm{N}=451)$ replicates the stated research.

The main research objective was to characterize the behaviour of Generation $Y$ (25-40 years) in the consumption of online content. The sub-objective was to identify the motives Generation $Y$ has for consuming online content, track the changes in viewing and searching for content, identify the new preferences in content consumption, use of voice search and viewership ratings for video content on social media.

We have put together the following research questions:

RQ1: What is the motivation for connecting to the Internet?

RQ2: What changes have occurred in viewing and retrieving online content over the last four years?

RQ3: What are some of the new preferences in the consumption of online content?

RQ4: How was voice search adapted to the Slovak conditions?

RQ5: What viewership ratings does video content have on social media?

The research questions aimed at analysing the specific preferred online content in Generation $Y$ at present and/or in the future were also focusing on artistic content. Based on our findings, we suggest some of the ways content marketing can be used in this area.

\section{Population}

The basic set, and/or population, is represented by the members of Generation $Y$ living in Slovakia. Some authors define the age range of this demographic cohort in the years 1976-1996, others prefer the range 1983-2000. However, there is no unanimous agreement among the authors regarding the starting and ending years; therefore, we decided to define the age range according to the study by Edelman Berland [2012] who classifies this generation with an age range of 1980-1995, i.e. this age group is aged 25-40. This generation is also known under the term "Millennials", "Generation Why", "Net-gen" or "iGeneration". It grew up with the digital technologies and during the de- 
velopment of social media, which also supports the finding that its members can be online almost continuously. Martin Buchtík, a sociologist and member of the Institute of Sociology of the Academy of Sciences of the Czech Republic [in Koníčková, 2019, online] claims that: "What most influenced this generation is technological progress. They have the technology in their genes, and Generation $Y$ is completely identified with the advent of the iPhone, laptops and tablets. He also adds the following: "Digital communication is very important for young people. $90 \%$ of young people aged 18 to 34 are using social networks, mostly Facebook".

The research by Edelman Berland [2012] also suggests that Generation $Y$ is very influential because 7 out of 10 believe that it is their duty to share their opinions about brands and positive or negative experience. They are surprisingly open-minded to branding and advertising if the brands use the correct approach, while only $3 \%$ think that all advertising is boring, and $80 \%$ want the brands to be fun. It was the first generation that grew up digitally, it has information at hand, and expects a two-way dialog with the preferred brands.

Based on the above, we consider Generation $Y$ to be the most appropriate population for our research on content marketing in the online environment. The members of this age group spend most of their time on the Internet, especially on social networks. They want their brands to be entertaining and they demand content with some added value. This is a great opportunity for the companies and non-profit organizations in terms of content marketing.

Generation $Y$ is represented in our study by a sub population that consisted of 451 respondents from all over Slovakia.

\section{Research method}

Due to our research focus and objectives, we have selected a quantitative exploratory research method - an electronic survey - to collect the necessary data. An electronic questionnaire became our research tool of choice. To select the sample, we used the random probability sampling method with the age range of $25-40$ as the main criterion for the selection of respondents. The pre-research was not conducted since we largely replicated the research titled "The Future of Content Marketing: How People Are Changing the Way They Read, Interact and Engage with Content". The validity and reliability of the research instrument was verified in the original research, and we did not address it any further.

The questionnaire contained two additional items aimed at a deeper understanding of the target set. The original questionnaire was translated from English in order to avoid the semantic shifts and increase the reliability of the instrument, and it was submitted to an independent expert for review. The questionnaire was created through the Survio. com website and distributed via Facebook because Facebook allows us to reach a large number of potential respondents from Generation Y. The data were processed by MS Excel, the results were evaluated using the methods of descriptive statistics, and they were graphically visualized.

The questionnaire consisted of 16 open-end, multiple choice and mixed type questions; it was viewed 2305 times and completed by 451 respondents.

\section{Analysis}

In the first question we focused on the motivation and/or reasons why the respondents access the Internet. The following table shows the resulting percentage values for each response. $66.9 \%$ of the respondents indicated chatting, visiting the forums etc. 
$61.3 \%$ of the respondents most often look for information and documents related to their hobbies and activities that are not directly related with the study. A total of $48.9 \%$ of the respondents said they go online to retrieve information necessary for their study and $36 \%$ of the respondents download software, music, movies, photos etc. $21.1 \%$ of the respondents' use the Internet mostly for fun and $10.4 \%$ create or manage a website, publish text, audio or video files. $8.4 \%$ of the respondents said they connect to the Internet for other reasons, such as work (4.2\%), online gaming (1.1\%), watching erotic movies $(0.9 \%)$, search for expert literature $(0.7 \%)$, watching TV shows $(0.7 \%)$, sale or purchase of products $(0.2 \%)$. The respondents were also asked to choose from multiple answers because we realize that situational context is detrimental to the motivation to connect to the Internet. The above findings suggest that Generation $Y$ spends most of their time on social networks where they spend their leisure time and communicate with friends.

They also connect to the Internet because they want to learn new things - even those that are not directly relevant to their study. This finding is also positively associated with the use of content marketing in which the audience is engaged by the companies or non-profit organization thanks to interesting content.

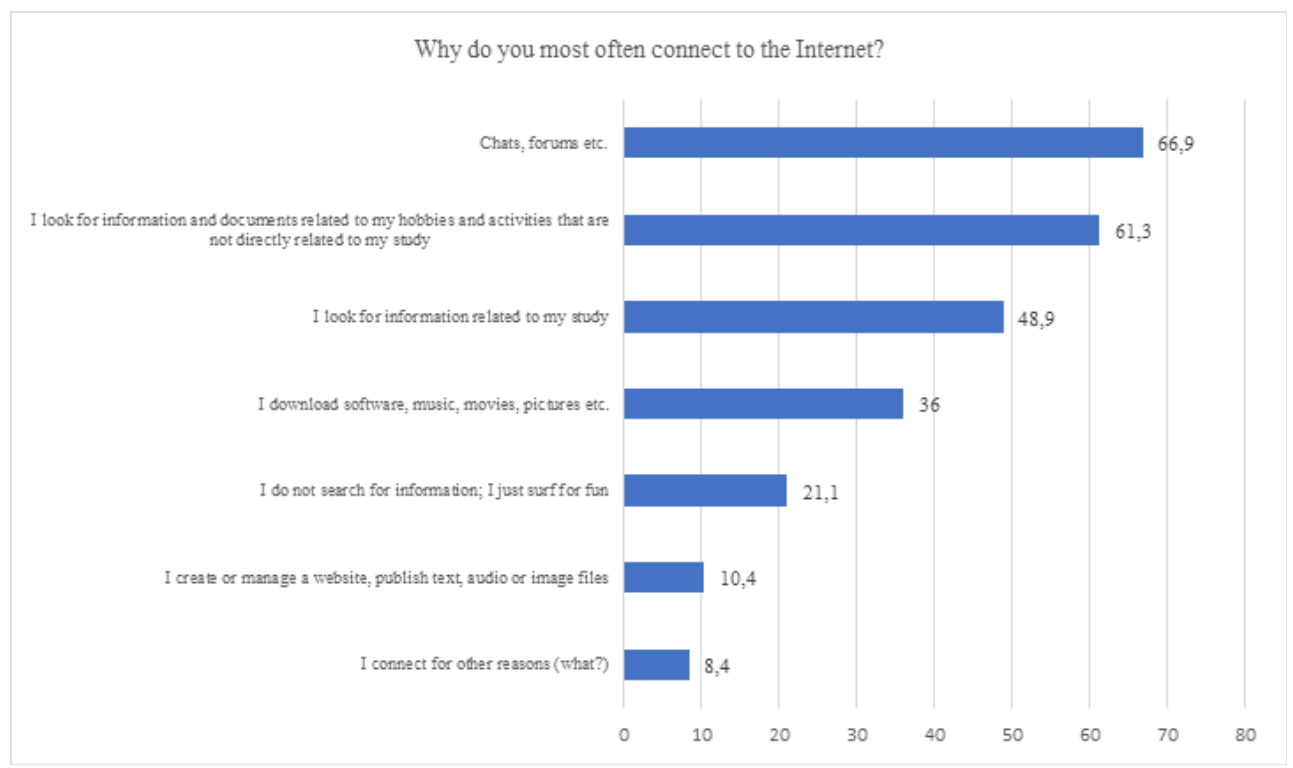

Figure 1. Motivation for Internet use 
Where are you currently looking for online business and lifestyle news, stories (articles)?

Where did you search for the same content 2 years ago?

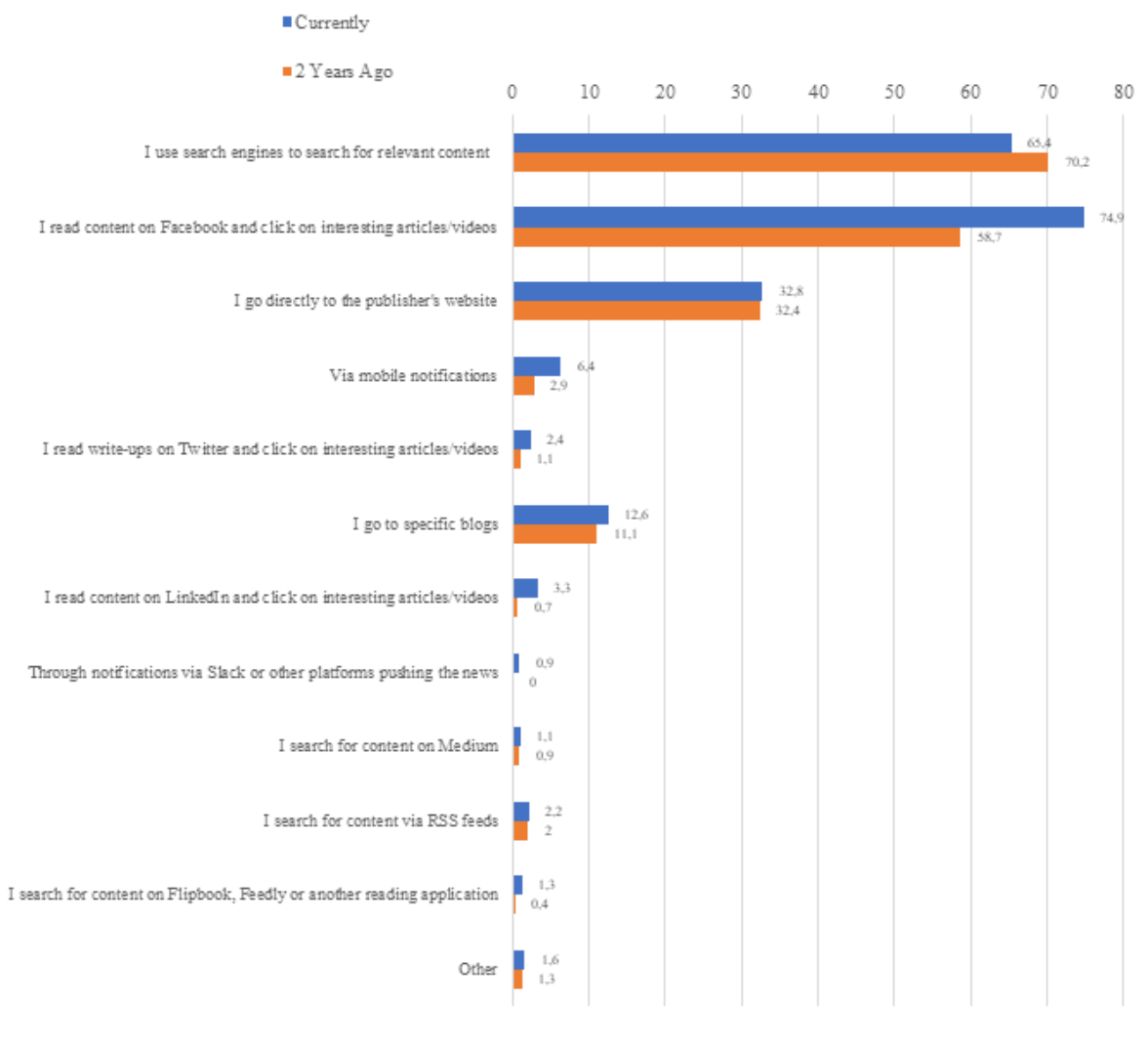

Figure 2. Methods to search for online content

In the next two questions, we were asking the respondents where they search for content nowadays and where they searched for the same content 2 years ago. Chart 2 shows that nowadays content is mostly searched for on Facebook $(74.9 \%)$, but 2 years ago the same content was searched for through the search engines (70.2\%). A significant change in the preferences of Generation $Y$ in the way they search for content can be noted over a relatively short period of time. The popularity and use of social networks continue to grow, and the content strategy and actual published content should adjust to it. $32.8 \%$ of the respondents answered that they search for content directly on the publisher's website, and almost the same number of respondents searched for content this way 2 years ago (32.4\%). The same applies to blogs where the situation has not changed significantly. Two years ago blogs were visited by $11.1 \%$ of the respondents, and the number rose slightly to $12.6 \%$.

Other possibilities were not strongly represented, which either implies their nonuse, or low awareness of the respective ways to search for content on the Internet. The answers to the multiple-choice questions included services such as Tumblr, Reddit, Instagram, YouTube and Trending stories on Getpocket. The Other option in the 2 years ago category included options such as Pokec.sk, Reddit and DVD rentals.

We noticed a general increase in each content searching option with the exception of search engines. This means that people want to consume content more widely and they are using an increasing amount of methods and ways to get to it. Therefore, the exclusive use of its website is not sufficient for a business or non-profit organization to reach the target audience. We also note that traditional search engines are being increasingly pushed aside by various social platforms and tools. We could mention Insta- 
gram and YouTube, which are gaining traction these days.

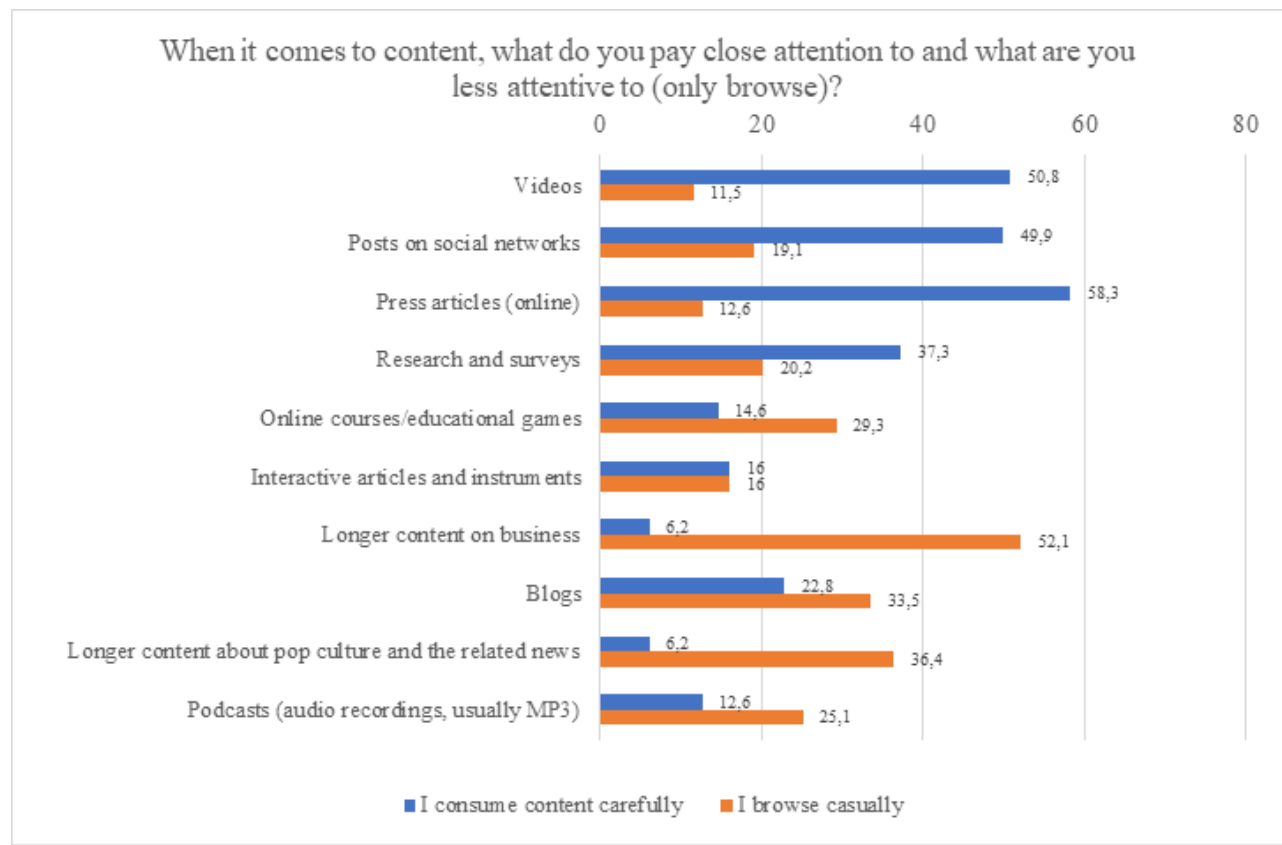

Figure 3. Attention to forms of content

The next two questions were related to the rate of interest in certain forms of content. We wanted to know what forms of content the recipients carefully pay attention to, and vice versa, what forms of content are only viewed casually or briefly. The results indicate that Generation $Y$ pays the greatest amount of attention to newspaper articles (58.3\%), videos (50.8\%), and posts on social networks (49.9\%) and research (37.3\%). On the contrary, a large proportion of respondents only pays limited attention to longer forms of business content (52.1\%) and pop culture (36.4\%), blogs (33.5\%), online courses and educational games (29.3\%) and podcasts $(25.1 \%)$.

The results indicate the significance of distinction between certain forms of content on the part of companies and non-profit organizations with respect to a specific audience. In other words, the companies must take into account not only the attractiveness of the content itself, but also its forms due to the specific target group of recipients. If a company is currently looking into making Generation $Y$ attentive to its products, services or ideas, it should prioritize videos and posts on social networks or online news articles as the forms of content marketing. However, interesting findings can be seen in the next research question where the current recommendations become obsolete and/or it is likely that the most preferred forms of online content consumption will decline in the future. 


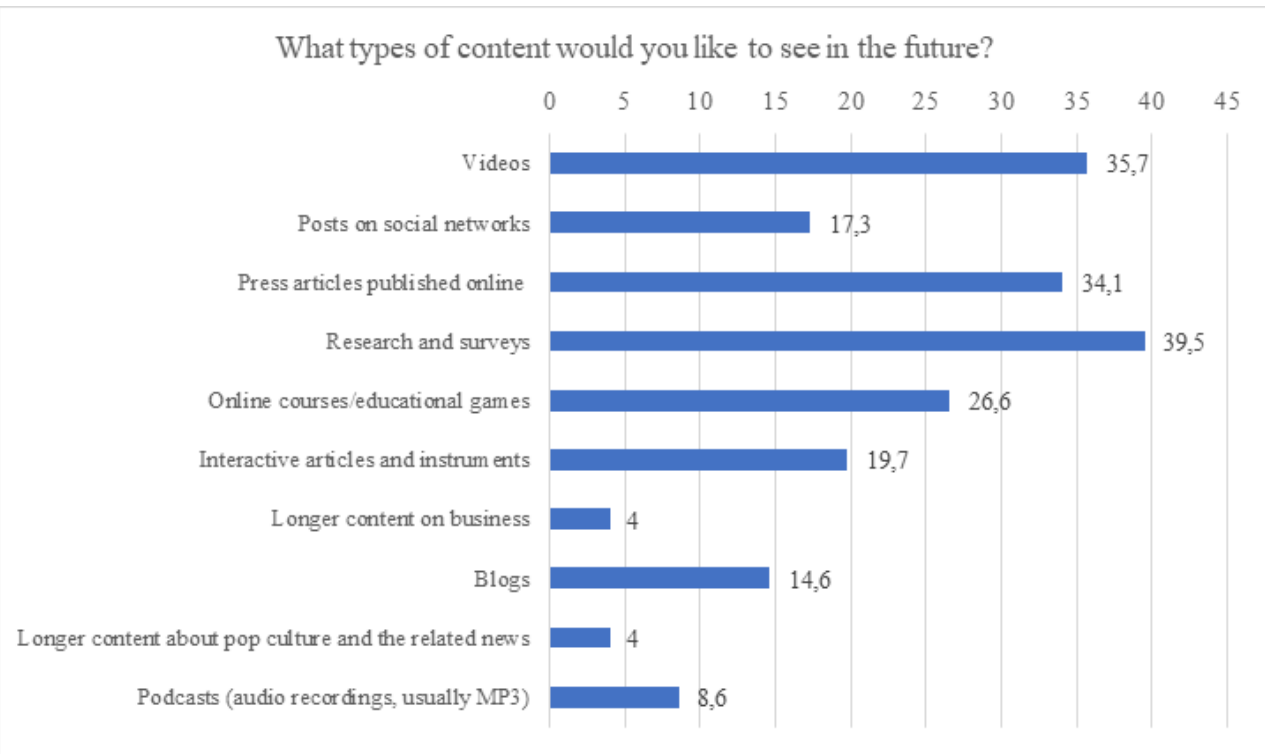

Figure 4. Preferred content in the future

In relation to the previous questions, we asked the respondents about the types of content they would like to see in the future. Research (39.5\%), videos (35.7\%) and newspaper articles published on the Internet (34.1\%) can be considered the most expected and/or preferred forms of content in the future. A slightly lower level of interest was noted regarding the online courses or educational games (26.6\%), interactive articles or instruments (19.7\%) and posts on social networks (17.3\%). The lowest level of interest was declared in the area of blogs (14.6\%), podcasts $(8.6 \%)$ and longer forms of content about business and pop culture ( $4 \%$ each).

It follows from these findings that compared to the current rate of attention of Generation $Y$ to the forms of content, we could see the expected increase in the forms such as online courses and educational games, interactive tools and research. On the contrary, a significant decline in reader preferences was noted in the posts on social networks, videos, newspaper articles published online, blogs, longer articles about business and pop culture and podcasts. Therefore, we recommend the businesses and non-profits to focus their production of content for on the currently preferred forms while continuously evaluating their level of attractiveness relative to the target audience. The current preferred forms of content may significantly change over time, especially in the dynamic environment of digital marketing communications. Therefore, the less preferred forms of content should not be completely excluded from the strategy of content marketing communication. The actual needs and trends in communication preferences of the given audience are important since there is no universal content or its form to capture the attention of every representative of the given target group. It is therefore necessary to create and publish various types and forms of content, which also fosters originality, novelty and variety in communication.

Due to our estimation of the habits of Generation $Y$ when browsing for content, we asked the respondents about the devices they use most for Internet access. A whopping $64.3 \%$ said that the primary device is their smartphone. In conjunction with tablets $(2.9 \%$ of the respondents), up to $67.2 \%$ of the respondents prefer accessing online content on a device with a mobile operating system. Therefore, the marketers should take note of the fact that the content will be most probably viewed on a mobile device and adapt it accordingly in the creation phase. This has to do with the optimization of websites for mobile devices. Only $32.8 \%$ of the surveyed respondents mostly use a PC or laptop. 
How do you want to be notified of published news?

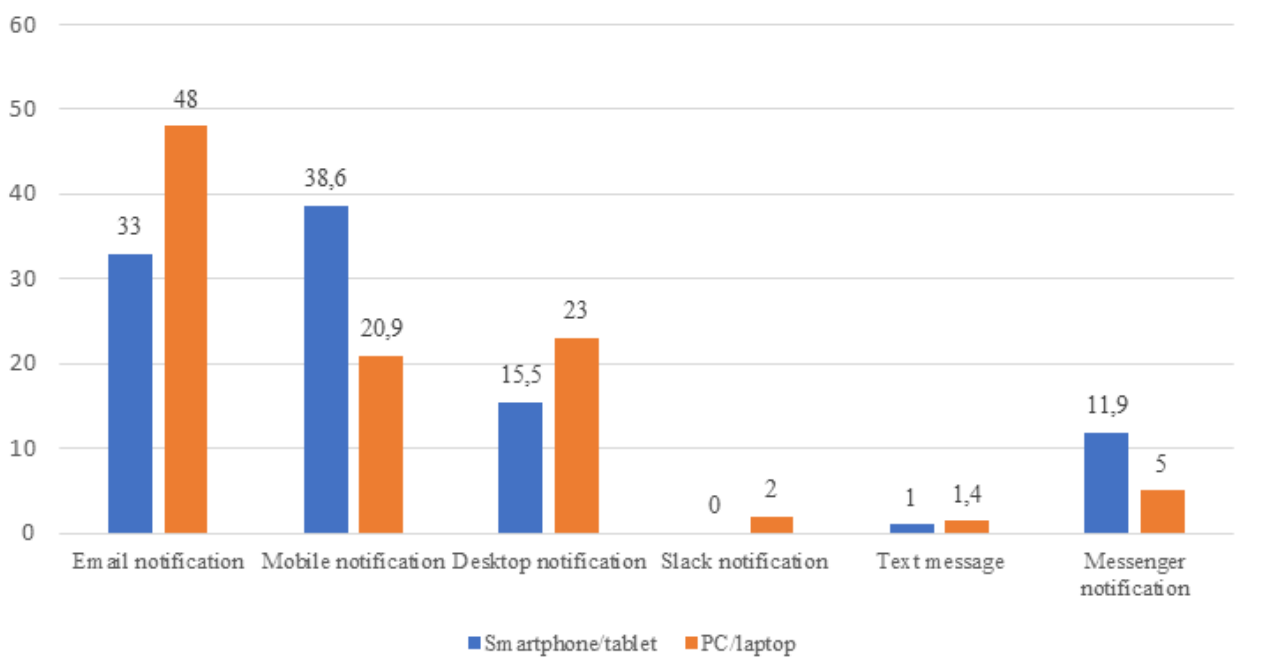

Figure 5. Preferred notification methods according to the primary device

The answers to the question "How do you want to be notified of published news?" were divided by the primary devices that the respondents use to access the Internet. This question only allowed one answer, and it comes as no surprise that most of the respondents who use a smartphone or tablet as their primary device want to be alerted via mobile notifications (38.6\%). E-mail notifications were indicated by $33 \%$ and desktop notifications by $15.5 \%$ of the respondents. A total of $11.9 \%$ wanted to be notified via the Messenger app and $1 \%$ of the respondents prefer text messaging. Notifications through Slack were not selected by any of the respondents. This result may be viewed in the context of low awareness of this platform/application in Slovakia. We expect that the Slovak users would rather choose Snapchat, WhatsApp and Viber.

The respondents who mainly use the PCs or laptops most frequently indicated the possibility of being notified by e-mail (48\%), desktop (23\%) and mobile phone $(20.9 \%)$ notifications. The respondents preferred the Messenger app notifications (5\%), Slack $(2 \%)$ and text messages (1.4\%) at a much lower rate.

In general, the best way to alert the audience to new content is an e-mail (37.9\%) or mobile alert (32.8\%). These two methods appear to be the most preferred by Generation $\mathrm{Y}$. The newer methods of notification, such as desktop notifications (18\%), Messenger $(9.5 \%)$ and Slack $(0.7 \%)$, have a rather small potential audience these days. However, we expect the audience to be more open to receiving such notifications on the published content in the future.

As the use of mobile devices is increasing significantly, we wondered how many of the surveyed use voice search, and/or to what extent is this function used by the representatives of Generation Y living in Slovakia. The results show that most of them do not use this service (Siri $91.6 \%$, Cortana $99.3 \%$ and Alexa $99.5 \%$ of the respondents). The respondents who do use voice search mostly indicated Siri: $4.3 \%$ use it every month, $2.3 \%$ every week, $1.4 \%$ every day and $0.5 \%$ several times a day. The data on the use of voice search is negligible (the highest attained value is $0.5 \%$ ) in the case of Cortana and Alexa. In our opinion, the reason behind these numbers is English as the language of communication, as well as the dominance of Android in the Slovak environment. In the future, however, we expect an increase in these numbers because the voice search technology is constantly improving. It is becoming a natural component in the smartphones and tab- 
lets and it enables the creation of smart homes. According to Martindale [2020] ${ }^{6}$, virtual assistants such as Cortana, Siri, Google Assistant and Alexa, are now a signature feature of smartphones and tablets. We're seeing them expand their software capabilities and platform support.

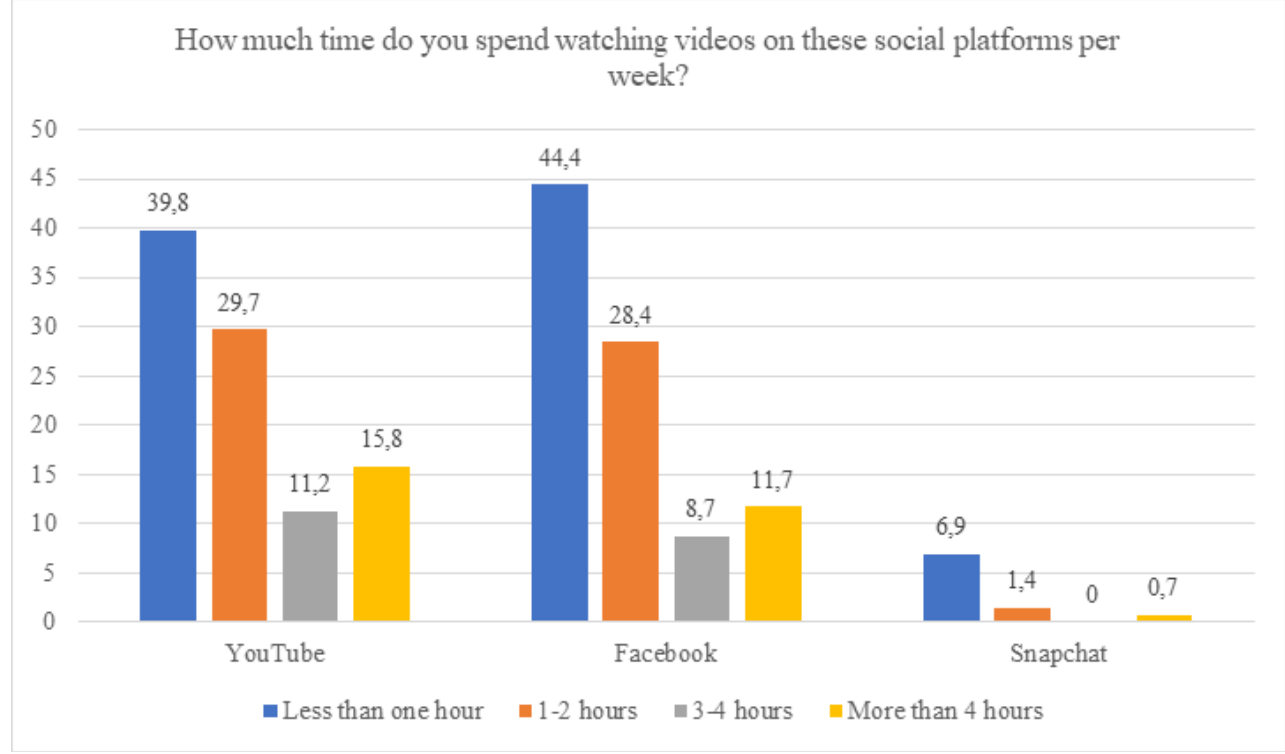

Figure 6. Watching videos on social platforms

In relation to the demand for video content, we investigated how much time the respondents spend watching the videos on YouTube, Facebook and Snapchat. Regarding YouTube, most respondents $(39.8 \%)$ stated that they view the content for less than an hour per week. The second most common response (29.7\%) was 1-2 hours per week. Up to $15.8 \%$ watch the videos on YouTube for more than 4 hours and $11.2 \%$ for $3-4$ hours a week. Only $3.5 \%$ of the respondents said they do not watch any videos on YouTube.

In the case of Facebook, the most common response was less than one hour, which was selected by up to $44.4 \%$ of the respondents. Up to $28.4 \%$ of the respondents watch the videos on this social network for $1-2$ hours a week and $11.7 \%$ of them do so for more than 4 hours. Up to $8.7 \%$ said that they watch the videos on Facebook for three to four hours a week, and only $6.8 \%$ do not watch any videos at all.

Following Chart 3 , which shows that up to $50.8 \%$ of the respondents pay careful attention to videos, and Chart 4 , which shows that $35.7 \%$ of the respondents would appreciate watching more videos in the future, we conclude that the marketers can use video as an important, high-quality and attractive tool in content marketing that addresses their offering and brands. The video content platform on Facebook is relatively new compared to YouTube, but Chart 6 shows that the viewership ratings are increasing very quickly.

Facebook has 1.69 billion of daily active users (as of August 2020) and over 8 billion average daily video views, while YouTube, which has nearly 67 million daily active users worldwide, reports almost 5 billion videos being watched every single day. ${ }^{7}$ It is also worth mentioning that Snapchat, a social network based on short videos with 238 million daily active users (as of August 2020) ${ }^{8}$, has recently surpassed Facebook in terms of

\footnotetext{
6 Available at: https://www.digitaltrends.com/computing/cortana-vs-siri-vs-google-now/ [online: August 7, 2020]

$7 \quad$ Available at: https://www.omnicoreagency.com/youtube-statistics/ [online: August 7, 2020] 8 Available at: https://www.statista.com/statistics/545967/snapchat-app-dau/ [online: August 7,2020 ]
} 
viewership ratings with around 18 billion daily video views worldwide ${ }^{9}$.

Based on the above, we decided to add this social platform alongside YouTube and Facebook compared to the original research. The results have shown that this social medium is not very popular among Generation $Y$ in Slovakia because up to $91 \%$ of the respondents do not watch videos on Snapchat at all, $6.9 \%$ watch them for less than an hour a week, $4.4 \%$ watch them 1-2 hours per week, none of the respondents selected the 3-4 hours option, and $0.7 \%$ watch them for more than 4 hours a week. Despite our findings, we conclude that the popularity of Snapchat continues to grow both worldwide and also in Slovakia, and we can expect the viewership ratings to rise in the future.

In comparison with other popular social media, Twitter has 152 million active daily users $^{10}$ and 2 billion videos are watched on this platform every day ${ }^{11}$. Instagram is actively used on a daily basis by more than 500 million users and the number of photos \& videos uploaded per day is upwards of 100 million. TikTok is a relatively new social platform (founded in 2016), and it specializes in sharing video content. Currently, its content is watched by more than 800 million monthly users, which instantly places it amongst the top social media platforms in the world in terms of sheer user figures. ${ }^{12}$ Therefore, this platform will become a major player in the area of video advertising in the future even in our geographic area.

\begin{tabular}{|l|c|c|c|}
\hline $\begin{array}{c}\text { Most popular social } \\
\text { media in } 2020\end{array}$ & Daily Active Users & Daily Video Views & $\begin{array}{c}\text { Year of Establish- } \\
\text { ment }\end{array}$ \\
\hline Facebook & 1.69 billion & 8 billion & 2004 \\
\hline YouTube & 67 million & 5 billion & 2005 \\
\hline Twitter & 152 million & 2 billion & 2006 \\
\hline Instagram & 500 million & 100 million & 2010 \\
\hline Snapchat & 238 million & 18 billion & 2011 \\
\hline TikTok & 27 million & 1 million & 2016 \\
\hline
\end{tabular}

Table 1. Social media users and video views

Source: Own processing according to Footnote 5-10

The comparison of social media in terms of the adequacy of use by a given company or non-profit organization must take into account the specific marketing objectives, target audience and its communication preferences and habits, as well as the capabilities and characteristics of the social platforms. If our intention is to publish video content for Generation Y, our research recommends to focus on Facebook and YouTube, but we should not forget the rapidly growing platforms such as Snapchat or TikTok, which are primarily specialized in disseminating video content.

According to R. Robinson [2019, online], "while on one hand, this explosion of social media platforms presents brands with unprecedented opportunities to reach growing audiences on emerging platforms, there's also an increasing challenge around how to best allocate time, resources, and attention among the sea of options now at the disposal of marketers around the world. No matter which social media sites you decide to spend your time on, you'll need to employ the right tools in order to be successful in

\footnotetext{
$9 \quad$ Available at: https://wallaroomedia.com/blog/snapchat/snapchat-statistics/ [online: August 7, 2020]

10 Available at: https://www.statista.com/statistics/242606/number-of-active-twitter-users-in-selected-countries/ [online: August 7, 2020]

11 Available at: https://blog.hootsuite.com/twitter-statistics/ [online: August 7, 2020]

12 Available at: https://spark.adobe.com/make/learn/top-social-media-sites/ [online: August 7 
growing an audience and achieving an ROI on your campaigns."13

We have also analysed the types of videos the respondents watch most in relation to the viewership ratings. Since the respondents provided a broad variety of answers in this open question, we divided them into the following categories. Most of the respondents watch music videos (66.1\%), and over half of the respondents watch tutorials (50.3\%). The favourite types also include sports videos (21.1\%), travel videos $(19.5 \%)$ and entertainment (19.3\%). Television, movies, TV shows and cartoons are watched by $11.3 \%$ and vlogs by $7.1 \%$ of the respondents. Other categories were selected by a smaller number of respondents (see Figure 7). Unfortunately, the category of arts does not belong to the preferred or frequently watched types of video content in Generation $Y$, which shows not only the need for a specific approach to communicating with artistically oriented audience (because it does not belong to mass audience), but also the need to increase the attractiveness and intensity of communications by the artistically oriented entities (artists or art institutions).

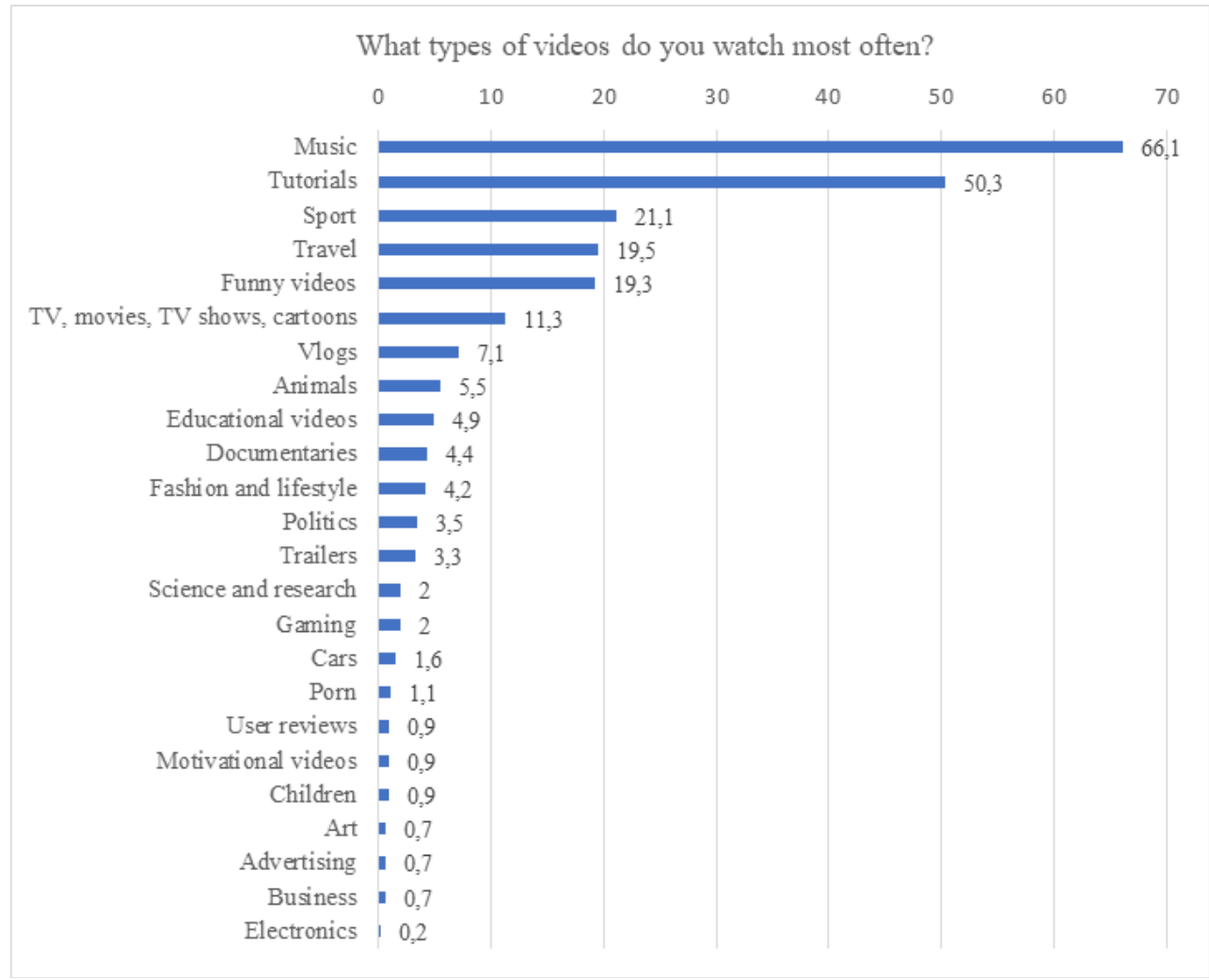

Figure 7. Most watched video types

We were also interested in the types of tutorials the respondents watch. Up to $36.5 \%$ of the respondents enjoy beauty tutorials (makeup, hair and nail tutorials), $35.7 \%$ of the respondents indicated the general answer "tutorials" or "DIY", 18.5\% watch cooking and baking tutorials, and $5.7 \%$ enjoy exercise tutorials. The tutorials focusing on photography, film-making and graphics were reported by $1.8 \%$ of the respondents. The fact that tutorials are popular among Generation $Y$ poses a huge advantage - and a challenge at the same time - for the marketers. The companies have the chance and opportunity to promote their products and the methods of their use through instructional videos. They can show their products to the audience and demonstrate their proper use and/or installation. In the non-profit sector, we can talk about the promotion of ideas and the 
creation processes (such as graffiti or street art), and the methods of implementation of various projects (installations, events, happenings) can be presented in the artistic sector. This also allows our audience to gain new knowledge and skills useful in their own line of work, and mediate artistic experiences to them. We think it is very likely that such people will search for such content themselves and further distribute or recommend it to their friends. Therefore, a tutorial and/or instructional video has a strong viral potential exploitable in the "for profit" and "non-profit" sector.

\section{Conclusions}

The present scientific study deals with the characteristics of the current state and future direction of content marketing in Slovakia and it is based on the design of the questionnaire survey titled "The Future of Content Marketing: How People Are Changing the Way They Read, Interact and Engage With Content", which was implemented by HubSpot in 2016 as an online survey of online users from around the world. The population of Slovak respondents $(\mathrm{N}=451)$ was used to describe the behaviour of Generation Y (2540 years) in the consumption of online content, and it also identified the motives behind the consumption. We also examined the changes in viewing and searching for content; we surveyed the current preferences in the consumption of content, level of use of voice search, and viewership ratings of video content and its various types on social media.

The Slovak respondents most often search for content via Facebook (74.9\%), search engines (65.4\%) and on the publisher's websites (32.8\%). When comparing these data with the situation two years ago, we see an increase in the use of Facebook by more than $16 \%$ at the expense of search engines.

When focusing on a particular type of content the people search for, we can see quite a difference in the content that attracts the audience. The respondents in Slovakia devote most attention to online newspaper articles (58.3\%), social media posts $(49.9 \%)$ and research (37.3\%). Other options were often referred to as those that the respondents just browse through but pay no detailed attention to.

In relation to the previous question, we also investigated the types of content people want to see in the future. The interviewed Slovaks would like to see more research (39.5\%), videos (35.7\%), newspaper articles (34.1\%) and online courses/educational games $(26.6 \%)$ in the future. These are followed by interactive articles or instruments $(19.7 \%)$, posts on social media (17.3\%) and blogs (14.6\%). Podcasts (8.6\%) and longer forms of content about business and pop culture ( $4 \%$ each) scored low.

The respondents go online mostly from their smartphones (up to $64.3 \%$ ), PCs or laptops (32.8\%) and tablets (2.9\%). These results were no surprise to us since the population consisted of members of Generation $Y$, or the so-called iGeneration. Some authors describe this generation as being online $24 / 7$ and not willing to give up their cell phones even for a day.

Another question was aimed at how the respondents want to be notified about the published news. These results depend on the primary device that is used to access the Internet most frequently. E-mail notifications are dominant however, this option was selected by $48 \%$ of the respondents using a computer and $33 \%$ of the respondents using a smartphone or tablet. The second most common response was mobile alerts (smartphone/tablet $-38.6 \%$, PC/laptop - 20.9\%). A significant proportion of the respondents would appreciate receiving desktop notifications (smartphone/tablet - 15.5\%, PC/laptop $-23 \%$ ). It is surprising that $11.9 \%$ of the respondents using a smartphone/tablet said they would prefer to be notified through a Messenger notification. We attribute this to the fact that Facebook is becoming very popular and people are spending most of their online time on this platform. Messenger is a paired application to receive messages from this social network. 
To provide a holistic view of content marketing, the surveyed areas also included the use of voice search. In our results, the data on Cortana and Alexa were almost negligible and the highest value was $0.5 \%$. The most widely used voice search service in Slovakia is Siri and it is used by $8 \%$ of the respondents (of which $4.3 \%$ use it monthly, $2.3 \%$ once per week, $1.4 \%$ daily and only $0.5 \%$ several times per day). It is surprising that more than $90 \%$ of the respondents in Slovakia do not use voice search at all. The function is still being improved and we can assume it has a potential for growth.

In relation to social networks, we also investigated how much time a week the respondents spend watching video on YouTube, Facebook and Snapchat because video scored high in the answers to the questions: When it comes to content, what type of content do you carefully follow? and What types of content you would like to see more in the future? The results are very much in favour of video, with only $3.4 \%$ of the respondents not following any videos on YouTube and $6.9 \%$ on Facebook. Compared to the original research, we added Snapchat as another option because it is gaining traction globally and it is becoming very popular. In some countries it even surpassed Facebook in terms of daily viewership ratings (An, 2016). However, according to our research data, it is still a novelty in Slovakia because up to $91.1 \%$ of the respondents do not watch videos on Snapchat.

However, it can be generally assumed that our entire set of results indicates that the conditions for the future development of content marketing are very favourable not only in Slovakia but also worldwide. Content marketing is currently receiving much more attention in Slovakia - both practical and theoretical - and specific job positions are created, and professional publications and scientific studies are published on the subject. However, most of them explore content marketing in terms of the specific content themes, or in terms of the posts published on social networks and their subsequent perception by the audience. We tried to tackle the issue from a different angle. Each company or non-profit organization has a different focus, so it is most natural that it produces different content.

According to C. Steele [2018 online], "in order to create engaging digital content, organizations in and culture sector should have been place in marketing team with at least one branding specialist. Since the arts and creative outlets influence the business sector, it only makes sense that cultural organizations similarly implement certain business strategies to carry out their own objectives. By integrating content marketing, arts and culture can be shared in a quicker, easier and more efficient way to multitudes of people on a global scale. If you manage an arts organization like a small gallery or an annual festival, you should make it easy for people to share their support by creating well-developed and engaging content. Offering compelling videos, updates on social networking sites, and informative blog posts are all sure-fire strategies that will lead people to share your content-and your art. In addition to generating shareable content, marketing teams in the arts and culture sector should also employ content as a means to quickly follow up with visitors or customers. Advertising your social channels, registering customers to an email list, or asking for their home address are all great ways to send out content that may turn them into loyal patrons. By integrating digital content strategies into your marketing plan, organizations in the arts and culture sector can form lasting relationships with their visitors or customers in a manner that inspires continuous support." ${ }^{\text {"14 }}$

The results of our research indicate that online (and social network) users are primarily interested in entertainment, communication with friends, self-expression in online forums, and therefore are willing to learn something new and interesting even if it is explicitly unrelated to their field of study or line of work. Today, the customers (and audiences) prefer to communicate with the companies and non-profit organizations in $14 \quad$ Available at: https://www.culturepartnership.eu/en/article/how-to-use-content-marketing-
to-share-arts [online: August 25, 2020] 
a two-way dialog and are open to new possibilities. The research results provide these stakeholders with some answers on where content should be published, what types of content are popular and attractive with Generation $Y$ and what content is welcome in the future. And although the voice search functionality is not used on a large scale, we suppose that an increase in its popularity with the ever-increasing use of mobile devices can be expected in the future. Voice search is linked to SEO (search engine optimization) because the voice results always offer one answer only. Those companies and non-profit organizations that wish to be that answer should put an emphasis on sophisticated content marketing, quality content and sophisticated key word analysis. Since the recipients are more attentive to video and would like to see more video in the future, we also took a closer look at the consumption of video. Our respondents were asked about the types of videos they watch most commonly, and we divided their answers into several categories. According to our findings, music, tutorials and/or instructional videos should dominate with the marketers, taking into account the specifics of the target audience. The emerging digital marketing agencies are offering a wide range of products and tools necessary for the current marketing communication in the online space, and content marketing is its inherent part.

Generation $Y$ encompasses the people aged 25 to 40 years, i.e. the young - probably studying in a college - and people in productive age. It represents the largest group among the generations and is characterized by a positive relationship with the media and digital technologies. If a company decides to devote its efforts to content marketing in the online space, it is likely that the content will also be consumed by members of this generation. Therefore, the results of our research may also be used as a kind of instruction or recommendation toolset for the companies and non-profit organizations to ensure that their content reaches the target audience and is created in a way that suits their preferences.

Further research can freely revolve around the possibility of extending the population by other age categories and comparing them. It would be interesting to see what content consumption preferences are preferred by the elderly or teenagers who are easily influenced by trends and brands. The companies also have the opportunity to use this research tool to directly identify the preferences of their audience, and/or to add more options to the answers if other methods are used to disseminate their content. Based on the analyses the companies can create a sophisticated content strategy, which is tailored to the target audience that consumes the created and published content.

\section{Acknowledgement}

This study is a partial output from the research project APVV-18-0257 - "Incubator of Multimedia Digital Production - Reciprocal Transfer of Science, Art and Creative Industries"

\section{References:}

AN, M. (2016), The Future of Content Marketing: How People Are Changing the Way They Read, Interact, and Engage With Content [online: December 15, 2019], https://research.hubspot.com/reports/the-future-of-content-marketing;

BAYEROVÁ, D. (2016), Slovník internetového marketingu. Persona. [online: December 15, 2019], https:// vceliste.cz/slovnik/persona/;

CLARKE, B. (2014), Content Marketing: How to build an audience that builds your business [online: December 15, 2019], http://www.copyblogger.com/content-marketing/;

EDELMAN - BERLAND, (2012), Study Finds Millennial Generation's Power to Influence Is Increasing. [online: December 15, 2019], http://www.edelman.com/news/study-finds-millennial-generations-power-to-influ- 
ence-is-increasing/;

HRDLIČKOVÁ, M. (2015), Kto je persona a kedy nahrádza ciel'ovú skupinu? [online: December 15, 2019], http://contentfruiter.sk/tvorba-obsahu/kto-je-persona-a-kedy-nahradza-cielovu-skupinu/;

KONÍČKOVÁ, J. (2017), Aká je generácia Y? [online: December 15, 2019], https://eduworld.sk/cd/jaroslava-konickova/2988/aka-je-generacia-y;

KUENN, A. AND KUENN, B. (2015), Content Marketing Works: 8 Steps to Transform Your Business, Phoenix, Vertical Measures Press.

PATEL, S. (2014), What's So Special about Content Marketing? Search Engine Journal. Boca Raton, Florida: Alpha Brand Media [online: December 15, 2019], https://www.searchenginejournal.com/whats-so-special-about-contentmarketing/49983/;

PULIZZI, J. (2013), Epic Content Marketing: How to Tell a Different Story, Break through the Clutter, and Win More Customers by Marketing Less, New York, McGraw Hill Professional.

RADIMÁK, E. (2014), Marketing na Facebooku: Web stránka a Facebook - prepojte ich. [online: December 15, 2019], http://www.contentmarketinghub.sk/marketing-na-facebooku-stranka-facebook-prepojte-ich/;

ROBINSON, R. (2019), The 7 Top Social Media Sites You Need to Care About in 2020. [online: December 15, 2019], https://spark.adobe.com/make/learn/top-social-media-sites/;

ROSE, R. (2018), An Alternative Approach to Developing Content Marketing Personas. [online: August 7, 2020], https://contentmarketinginstitute.com/2018/04/alternative-content-marketing-personas/;

ŘEZNíČEK J. AND PROCHÁZKA T. (2014), Obsahový marketing: Nakrmte Internet svým obsahem, Brno, Computer Press.

STEELE, C. (2018), How to use content marketing to share arts and culture, [online: August 25, 2020], https:// www.culturepartnership.eu/en/article/how-to-use-content-marketing-to-share-arts;

ZAMBITO, T. (2013), What is a buyer persona? Why the original definition still matters to B2B, [online: December 15, 2019], http://tonyzambito.com/buyer-persona-original-definition-matters/.;

\section{Online Sources}

https://www.digitaltrends.com/computing/cortana-vs-siri-vs-google-now/ [online: August 7, 2020]

https://www.omnicoreagency.com/youtube-statistics/ [online: August 7, 2020]

https://www.statista.com/statistics/545967/snapchat-app-dau/ [online: August 7, 2020]

https://wallaroomedia.com/blog/snapchat/snapchat-statistics/ [online: August 7, 2020]

https://www.statista.com/statistics/242606/number-of-active-twitter-users-in-selected-countries/ [online: August 7, 2020]

https://blog.hootsuite.com/twitter-statistics/ [online: August 7, 2020]

https://www.culturepartnership.eu/en/article/how-to-use-content-marketing-to-share-arts [online: August 25, 2020] 